Research

\title{
Meperidine and skin surface warming additively reduce the shivering threshold: a volunteer study
}

\author{
Oliver Kimberger ${ }^{1}$, Syed Z Ali ${ }^{1}$, Monica Markstaller ${ }^{1}$, Sandra Zmoos ${ }^{1}$, Rolf Lauber ${ }^{1}$, \\ Corinne Hunkeler ${ }^{1}$ and Andrea Kurz ${ }^{1,2}$
}

\author{
1Department of Anaesthesiology, University of Bern, CH-3010 Bern, Switzerland \\ 2Outcomes Research Institute, University of Louisville, 2301 S 3RD St, Louisville, KY 40292-2001, USA
}

Corresponding author: Oliver Kimberger, study@kimberger.at

Received: 6 Dec 2006 Revisions requested: 30 Jan 2007 Revisions received: 12 Feb 2007 Accepted: 23 Feb 2007 Published: 23 Feb 2007

Critical Care 2007, 11:R29 (doi:10.1186/cc5709)

This article is online at: http://ccforum.com/content/11/1/R29

(c) 2007 Kimberger et al.; licensee BioMed Central Ltd.

This is an open access article distributed under the terms of the Creative Commons Attribution License (http://creativecommons.org/licenses/by/2.0), which permits unrestricted use, distribution, and reproduction in any medium, provided the original work is properly cited.

\begin{abstract}
Introduction Mild therapeutic hypothermia has been shown to improve outcome for patients after cardiac arrest and may be beneficial for ischaemic stroke and myocardial ischaemia patients. However, in the awake patient, even a small decrease of core temperature provokes vigorous autonomic reactionsvasoconstriction and shivering-which both inhibit efficient core cooling. Meperidine and skin warming each linearly lower vasoconstriction and shivering thresholds. We tested whether a combination of skin warming and a medium dose of meperidine additively would reduce the shivering threshold to below $34^{\circ} \mathrm{C}$ without producing significant sedation or respiratory depression.

Methods Eight healthy volunteers participated on four study days: (1) control, (2) skin warming (with forced air and warming mattress), (3) meperidine (target plasma level: $0.9 \mu \mathrm{g} / \mathrm{ml}$ ), and (4) skin warming plus meperidine (target plasma level: $0.9 \mu \mathrm{g} /$ $\mathrm{ml})$. Volunteers were cooled with $4^{\circ} \mathrm{C}$ cold Ringer lactate infused over a central venous catheter (rate $\approx 2.4^{\circ} \mathrm{C} /$ hour core

temperature drop). Shivering threshold was identified by an increase of oxygen consumption ( $+20 \%$ of baseline). Sedation was assessed with the Observer's Assessment of Alertness/ Sedation scale.

Results Control shivering threshold was $35.5^{\circ} \mathrm{C} \pm 0.2^{\circ} \mathrm{C}$. Skin warming reduced the shivering threshold to $34.9^{\circ} \mathrm{C} \pm 0.5^{\circ} \mathrm{C}(p$ $=0.01$ ). Meperidine reduced the shivering threshold to $34.2^{\circ} \mathrm{C}$ $\pm 0.3^{\circ} \mathrm{C}(p<0.01)$. The combination of meperidine and skin warming reduced the shivering threshold to $33.8^{\circ} \mathrm{C} \pm 0.2^{\circ} \mathrm{C}(p$ $<0.01)$. There were no synergistic or antagonistic effects of meperidine and skin warming $(p=0.59)$. Only very mild sedation occurred on meperidine days.

Conclusion A combination of meperidine and skin surface warming reduced the shivering threshold to $33.8^{\circ} \mathrm{C} \pm 0.2^{\circ} \mathrm{C}$ via an additive interaction and produced only very mild sedation and no respiratory toxicity.

\section{Introduction}

Considerable evidence in animals indicates that mild hypothermia provides substantial protection against cerebral [1-4] and myocardial $[5,6]$ ischaemia. In humans, mild hypothermia has been shown to improve neurologic outcome and to reduce mortality after cardiac arrest $[7,8]$.

Mild hypothermia with core temperatures between $33^{\circ} \mathrm{C}$ and $34^{\circ} \mathrm{C}$ is relatively easy to induce during general anaesthesia because anaesthetics profoundly impair thermoregulatory responses [9-12]. However, induction of mild hypothermia in

ischaemic stroke may be difficult. Minute reductions $\left(>0.2^{\circ} \mathrm{C}\right)$ in core temperature trigger aggressive autonomic reactionsnamely, arteriovenous shunt vasoconstriction and shiveringwhich per se impair efficient core cooling. Consequently, to lower the vasoconstriction and shivering thresholds, numerous studies have searched for drugs and drug combinations, including meperidine [13], buspirone [14], dexmedetomidine [15], clonidine [16], nefopam [17], and several others. Furthermore, non-pharmacological treatments-arm and face warming [18] or whole-body skin warming[19]-have been investigated with regard to their impact on thermoregulatory thresholds.
\end{abstract} awake patients after acute myocardial infarction or acute

$\overline{\mathrm{CV}}=$ coefficient of variation; IS = internal standard; OAA/S = Observer's Assessment of Alertness/Sedation. 
Meperidine, in contrast to other opioids, possesses additional anti-shivering action at equianalgesic doses and inhibits shivering twice as much as vasoconstriction [13,20]. However, when meperidine is used as a single drug, large plasma concentrations are needed to reduce the shivering threshold to below $34^{\circ} \mathrm{C}$. These high plasma concentrations can cause significant respiratory depression and sedation and mandate close patient monitoring in an intensive care environment. They are thus not ideal in patient populations in which continuous evaluation of neurologic functioning is a major diagnostic and treatment approach.

In contrast, skin warming $[19,21]$ efficiently lowers thermoregulatory thresholds without causing side effects. The skin contributes approximately $20 \%$ to the control of each thermoregulatory threshold $[19,22]$, but skin surface warming alone is not sufficient to allow induction of mild hypothermia $\left(33^{\circ} \mathrm{C}\right.$ to $\left.34^{\circ} \mathrm{C}\right)$ with catheter or intravenous fluid cooling. However, a combination of skin surface warming and a medium dose of meperidine $(\approx 0.9 \mu \mathrm{g} / \mathrm{ml}$ plasma level) might additively decrease the shivering threshold to below $34^{\circ} \mathrm{C}$. We therefore tested the hypothesis that the combination of meperidine and skin surface warming decreases the shivering threshold to below $34^{\circ} \mathrm{C}$ via an additive interaction without causing significant sedation or respiratory toxicity.

\section{Materials and methods}

After obtaining approval by the Institutional Review Board of the University Hospital of Bern and written informed consent, we studied eight healthy volunteers on four days. Morphometric characteristics were age of $23 \pm 2$ years, weight of $68.6 \pm$ $9.4 \mathrm{~kg}$, height of $177 \pm 7.5 \mathrm{~cm}$, and body mass index of $22 \pm$ 2. The volunteers fasted eight hours before the experiment. During treatment, they were minimally clothed and rested in a supine position on a standard patient bed equipped with a water mattress.

\section{Treatment protocol}

All experiments were started between 8:30 and 9:00 a.m. to avoid any interference with thermoregulatory circadian fluctuations. After arrival in the volunteer laboratory, volunteers were randomly assigned to one of the four study days by means of a computer-generated randomisation list:

\section{Control day: Placebo infusion, no skin warming.}

2. Skin warming: The skin surface was warmed with a forcedair warming system (Bair Hugger; Arizant Inc., Eden Prairie, MN, USA) and a circulating water mattress (Medi-Therm III; Gaymar Industries, Inc., Orchard Park, NY, USA) set at maximum temperature $\left(43^{\circ} \mathrm{C}\right.$ and $41^{\circ} \mathrm{C}$, respectively). Subsequently mean skin temperature was maintained at $\approx 35.8^{\circ} \mathrm{C}$ throughout the study.
3. Meperidine (target plasma level: $0.9 \mu \mathrm{g} / \mathrm{ml}$ ): Meperidine was administered intravenously using an infusion regimen based on previously published pharmacokinetic data $[23,24]$.

4. Meperidine (target plasma level: $0.9 \mu \mathrm{g} / \mathrm{ml}$ ) plus skin warming (forced air plus water mattress) as described above.

A central venous catheter was inserted in the volunteer's left antecubital vein and used for blood sampling and infusion of cold Ringer lactate. For meperidine administration, an intravenous catheter was inserted into the right antecubital vein.

Once stable meperidine plasma levels and/or stable mean skin temperature was established on each study day and active arteriovenous shunt vasodilation was confirmed, lactated Ringer solution cooled to $\approx 4^{\circ} \mathrm{C}$ was infused on all study days at rates sufficient to decrease tympanic membrane temperature $\approx 2.4^{\circ} \mathrm{C} /$ hour (that is, $\approx 0.2^{\circ} \mathrm{C}$ every five minutes). The core temperature cooling rate was restricted to less than $2.5^{\circ} \mathrm{C} /$ hour because this rate was unlikely to trigger any dynamic thermoregulatory responses [25]. Fluid was given until the shivering threshold was identified or a total of up to $80 \mathrm{ml} / \mathrm{kg}$ of fluid was administered. Each study day ended upon detection of shivering. Subsequently, the volunteers were warmed until they were comfortable and had recovered from meperidine administration. Volunteers had an interval of at least 48 hours between study days; before the start of treatment, a blood sample was drawn to ensure that all meperidine remaining from previous study days had been eliminated.

\section{Measurements}

Heart rate was measured continuously by means of an electrocardiogram, and blood pressure was determined using a noninvasive method at 10 minute intervals at the left arm. Core temperature was recorded from the tympanic membrane by means of Mon-a-Therm ${ }^{\circledR}$ thermocouples (Mallinckrodt, Hazelwood, MO, USA). The tympanic probe was inserted by the volunteers until they felt the thermocouple touch the tympanic membrane; appropriate placement was confirmed when volunteers detected gentle rubbing of the attached wire. Additionally, tympanic probes were inserted into both ears, and a difference of less than or equal to $0.2^{\circ} \mathrm{C}$ confirmed correct placement. The aural canal was occluded with cotton, the probe was securely taped in place, and a gauze bandage was positioned over the external ear. Mean skin surface temperature was determined from 15 area-weighted sites [26].

All temperatures were recorded from thermocouples connected to calibrated Iso-Thermex ${ }^{\circledR} 16$ channel electronic thermometers (Columbus Instruments, Columbus, $\mathrm{OH}, \mathrm{USA}$ ) that have an accuracy of $0.1^{\circ} \mathrm{C}$ and a precision of $0.01^{\circ} \mathrm{C}$. Right index fingertip blood flow was quantified using volume plethysmography [27]. All measures of flow were recorded at fiveminute intervals. Vasoconstriction threshold was defined by the core temperature triggeringa fingertip flow of $\approx 1 \mathrm{ml}$ 
minute, which roughly corresponds to a forearm-minus-fingertip skin temperature gradient near $0^{\circ} \mathrm{C}$ and indicates mild vasoconstriction [27].

Oxygen consumption was measured by a $\mathrm{Vmax}^{\mathrm{TM}} 29 \mathrm{n}$ metabolic monitor (SensorMedics Corporation, Yorba Linda, CA, USA). Measurements were recorded every minute. A sustained increase in oxygen consumption of $20 \%$ above baseline identified the shivering threshold. The shivering and vasoconstriction thresholds were determined post hoc by an investigator blinded to treatment and core temperature.

As in previous studies, the level of sedation was assessed using the Observer's Assessment of Alertness/Sedation (OAA/S) scale [28] (Table 1). Thermal comfort was evaluated at 10-minute intervals with a $100 \mathrm{~mm}$-long visual analogue scale. Zero millimetres was defined as the worst imaginable cold, $50 \mathrm{~mm}$ as thermal comfort, and $100 \mathrm{~mm}$ as the worst imaginable heat. Both scores were obtained at 10-minute intervals throughout cooling. Venous blood was sampled at three time points: before the start of meperidine infusion (to ensure that no meperidine plasma levels remained from previous study days) and at each thermoregulatory threshold for measurement of meperidine plasma concentrations.

\section{Meperidine plasma level analysis}

Blood samples were centrifuged at $4^{\circ} \mathrm{C}(2,000 \mathrm{~g}, 30$ minutes $)$, and the supernatant plasma was transferred to glass vials with a screw cap and stored at $-20^{\circ} \mathrm{C}$ until analysis. Prior to extraction, plasma samples were allowed to thaw at room temperature. To $0.2 \mathrm{ml}$ of plasma, $200 \mathrm{ng}$ of piperidolate (SigmaAldrich, St. Louis, MO, USA) as internal standard (IS) and 0.05 $\mathrm{ml} 1 \mathrm{~N}$ sodium hydroxide solution were added and vortexed (5 seconds). Six tenths of a millilitre of a heptane-ethylacetate mixture $(1: 1, \mathrm{vol} / \mathrm{vol})$ was added and vortexed for 30 seconds. The phases were separated by standing at room temperature for three minutes and centrifugation (1,300 $\mathrm{g}$, three minutes). The water phase was flash-frozen in a 2-propanol dry ice bath. The organic phase was decanted into a second tube and dried under a gentle stream of nitrogen in a water bath (approximately $40^{\circ} \mathrm{C}$ ). The residues were redissolved in $0.1 \mathrm{ml}$ of extraction mixture, and $1 \mu \mathrm{l}$ was injected splitless into the gaschromatograph (Agilent 6890; Agilent Technologies, Inc., Santa Clara, CA, USA) equipped with a mass selective detector. The capillary column was a VF-Xms (Varian, Inc., Palo Alto, CA, USA) with a length of $12 \mathrm{~m}$, an inner diameter of $0.2 \mathrm{~mm}$, and a film thickness of $0.33 \mu \mathrm{m}$. The carrier gas was helium at a flow rate of $1.0 \mathrm{ml} /$ minute. Operating temperatures were $250^{\circ} \mathrm{C}$ for the injector, $280^{\circ} \mathrm{C}$ for the detector transfer line, and $100^{\circ} \mathrm{C}$ for the oven, which increased $\left(30^{\circ} \mathrm{C} /\right.$ minute) to $300^{\circ} \mathrm{C}$ and was held at that temperature for six minutes. The mass selective detector was operated in the electron impact mode $(70 \mathrm{eV})$ with selected ion monitoring with a dwell time of $100 \mathrm{~ms}$. The data were processed with proprietary mass spectrometer control software (HP G1701AA). The ions for quantitation were $\mathrm{m} / \mathrm{z} 247$ for meperidine and m/z 165 for the IS. Calibration curves with spiked and extracted plasma passed through the origin and were linear in the calibration range of 0.4 to $3.2 \mu \mathrm{g} / \mathrm{ml}$, and correlation coefficients were more than 0.98 . Coefficients of variation (CVs) of intra-day reproducibility ( $n=5)$ were $3.1 \%, 3.2 \%$, and $4.4 \%$ for meperidine in control samples containing $2.1,1.3$, and $0.7 \mu \mathrm{g} / \mathrm{ml}$, respectively. Intraday CVs were $3.5 \%, 3.6 \%$, and $5.3 \%$ at the same concentrations, respectively. The limit of quantitation at a signal-to-noise ratio of $10: 1$ was $0.1 \mu \mathrm{g} / \mathrm{ml}$. The recovery of meperidine and IS was more than $98 \%$.

\section{Statistical analysis}

Ambient temperature and physiological responses on each study day were first averaged for each volunteer; data obtained between the onset of shivering noticed by the observer and clinically relevant shivering (oxygen consumption $+20 \%$ ) were also included. The resulting values were then averaged among volunteers. Data were tested for normal distribution by means of Q-Q plot and Shapiro-Wilk test. All data were normally distributed. Results of the four study days and meperidine levels were compared using the Friedman test and the Student-Newman-Keuls test.

Interaction between the two treatments was evaluated using analysis of variance for repeated measurements [29]. A signif-

Table 1

\begin{tabular}{|c|c|c|c|c|}
\hline Sub-score & Responsiveness & Speech & Facial expression & Eyes \\
\hline 5 & Responds readily to name spoken in normal tone & Normal & Normal & Clear, no ptosis \\
\hline 4 & Lethargic response to name spoken in normal tone & Mild slowing or thickening & Mild relaxation & Glazed or mild ptosis \\
\hline 3 & Responds only after name is spoken loudly and/or repeatedly & Slurring or prominent slowing & Marked relaxation & Glazed and marked ptosis \\
\hline 2 & Responds only after mild prodding or shaking & Few recognised words & & \\
\hline 1 & Does not respond to mild prodding or shaking & & & \\
\hline
\end{tabular}

The final score is the sum of the Responsiveness, Speech, Facial expression, and Eyes component scores. Thus, a 'wide awake' score $=20$ and a 'deeply sedated' score $=9$. 
icant interaction (antagonism or synergism) was indicated by a statistically significant interaction term between the factors 'meperidine' and 'skin warming.' A non-significant interaction term indicated an additive effect. All results are expressed as means \pm standard deviations; differences are considered statistically significant when $p$ is less than 0.05 . SPSS 11.0 (SPSS Inc., Chicago, IL, USA) was used for statistical analysis, and Graphpad Prism 4.0 (GraphPad Software, Inc., San Diego, CA, USA) was used for figures.

\section{Results}

Physiological or ambient variables were comparable on the four study days (Table 2). All volunteers were vasodilated before the cold-fluid infusion was started. There was no difference for meperidine plasma levels between the meperidine day and the meperidine plus skin warming day $(p=0.42)$, and meperidine plasma levels remained stable throughout the experiments. Meperidine produced only mild sedation; OAA/S scale was not significantly decreased on the meperidine day ( $p=0.10$, versus control) or the meperidine plus skin warming day $(p=0.10$, versus control) (Table 2$)$.

\section{Effect of meperidine and skin warming on the vasoconstriction threshold}

Skin warming reduced the vasoconstriction threshold by $0.4^{\circ} \mathrm{C} \pm 0.3^{\circ} \mathrm{C}(p<0.01)$. Meperidine reduced the vasoconstriction threshold by $-0.7^{\circ} \mathrm{C} \pm 0.3^{\circ} \mathrm{C}(p<0.01)$. The combination of meperidine and skin warming significantly reduced the vasoconstriction threshold by $-0.9^{\circ} \mathrm{C} \pm 0.2^{\circ} \mathrm{C}(p<0.01$; Table 2; all values compared to control day).

\section{Effect of meperidine and skin warming on shivering threshold}

Skin warming reduced the shivering threshold by $-0.6^{\circ} \mathrm{C} \pm$ $0.5^{\circ} \mathrm{C}(p=0.01)$. Meperidine reduced the shivering threshold by $-1.3^{\circ} \mathrm{C} \pm 0.3^{\circ} \mathrm{C}(p<0.01)$. The combination of meperidine and skin warming reduced the shivering threshold by $-1.7^{\circ} \mathrm{C} \pm$ $0.3^{\circ} \mathrm{C}(p<0.01$; Table 2; Figure 1 ; all values compared to control day).

There was no interaction between meperidine and skin warming for vasoconstriction $(p=0.20)$ or shivering $(p=0.59)$ thresholds. A combination of both treatments thus additively reduced the shivering threshold.

\section{Discussion}

This study demonstrates that a combination of meperidine and skin surface warming additively reduces the shivering threshold to below $34^{\circ} \mathrm{C}$ and produces only very mild sedation and no respiratory toxicity. The combination of meperidine and skin surface warming can thus be recommended for facilitating the application of therapeutic mild hypothermia in the awake patient.

In humans, mild hypothermia for 24 hours has been shown to improve outcome after cardiac arrest $[7,8]$ and the application of mild hypothermia has been advised by the International Liaison Committee on Resuscitation [30] and the European Resuscitation Council [31]. Currently, several clinical mild hypothermia studies in patients with ischaemic heart injury, brain trauma, or ischaemic stroke are ongoing.

Table 2

\section{Confounding factors and results}

\begin{tabular}{|c|c|c|c|c|}
\hline & Control & Skin warming & Meperidine & Combined \\
\hline Ambient temperature $\left({ }^{\circ} \mathrm{C}\right)$ & $22.6 \pm 0.46$ & $22.3 \pm 0.5$ & $22.1 \pm 0.7$ & $22.3 \pm 0.7$ \\
\hline Mean arterial pressure $(\mathrm{mm} \mathrm{Hg})$ & $89.3 \pm 7.1$ & $87.9 \pm 10.9$ & $87.8 \pm 9.4$ & $88.6 \pm 5.4$ \\
\hline Heart rate (beats per minute) & $65.3 \pm 7.8$ & $67.9 \pm 11.7$ & $62.5 \pm 8.2$ & $69.4 \pm 9.6$ \\
\hline $\mathrm{SpO}_{2}$ (percentage) & $99.3 \pm 0.8$ & $99.1 \pm 0.6$ & $98.6 \pm 1.0$ & $98.6 \pm 0.9$ \\
\hline $\mathrm{PCO}_{2}(\mathrm{~mm} \mathrm{Hg})$ & $5.1 \pm 0.3$ & $5.1 \pm 0.5$ & $5.0 \pm 0.4$ & $5.2 \pm 0.8$ \\
\hline Ringer lactate $(\mathrm{ml} / \mathrm{kg})$ & $22.0 \pm 4.5$ & $50.6 \pm 13.0^{a}$ & $58.4 \pm 12.8^{a}$ & $84.3 \pm 6.8^{a}$ \\
\hline Meperidine $(\mu \mathrm{g} / \mathrm{ml})$ & $\mathrm{N} / \mathrm{A}$ & $\mathrm{N} / \mathrm{A}$ & $0.98 \pm 0.20$ & $0.96 \pm 0.19$ \\
\hline Thermal comfort VAS & $26.9 \pm 5.0$ & $28.9 \pm 9.3$ & $34.8 \pm 8.6^{b}$ & $43.6 \pm 9.6^{c}$ \\
\hline OAA/S scale & $20 \pm 0$ & $19.9 \pm 0.3$ & $19.5 \pm 0.7$ & $19.4 \pm 0.7$ \\
\hline Mean skin temperature start $\left({ }^{\circ} \mathrm{C}\right)^{d}$ & $35.7 \pm 0.4$ & $35.8 \pm 0.3$ & $35.8 \pm 0.2$ & $35.8 \pm 0.2$ \\
\hline Mean skin temperature end $\left({ }^{\circ} \mathrm{C}\right)^{\mathrm{e}}$ & $34.3 \pm 0.7$ & $35.6 \pm 0.3^{a}$ & $33.8 \pm 0.6$ & $35.4 \pm 0.3^{a}$ \\
\hline Core temperature vasoconstriction $\left({ }^{\circ} \mathrm{C}\right)$ & $36.5 \pm 0.2$ & $36.1 \pm 0.2^{a}$ & $35.8 \pm 0.3^{a}$ & $35.6 \pm 0.3^{a}$ \\
\hline Core temperature shivering $\left({ }^{\circ} \mathrm{C}\right)$ & $35.5 \pm 0.2$ & $34.9 \pm 0.5^{c}$ & $34.2 \pm 0.3^{a}$ & $33.8 \pm 0.2^{a}$ \\
\hline
\end{tabular}

${ }^{a} p<0.01,{ }^{b} p=0.04,{ }^{c} p=0.01$ (versus control). dMean skin temperature measured immediately before intravenous cooling. eMean skin temperature measured at the end of cooling. N/A, not applicable; OAA/S: Observer's Assessment of Alertness/Sedation; PCO 2 , partial pressure of carbon dioxide; $\mathrm{SpO}_{2}$, oxygen saturation as measured by pulse oximetry; VAS, visual analogue scale. 
Figure 1

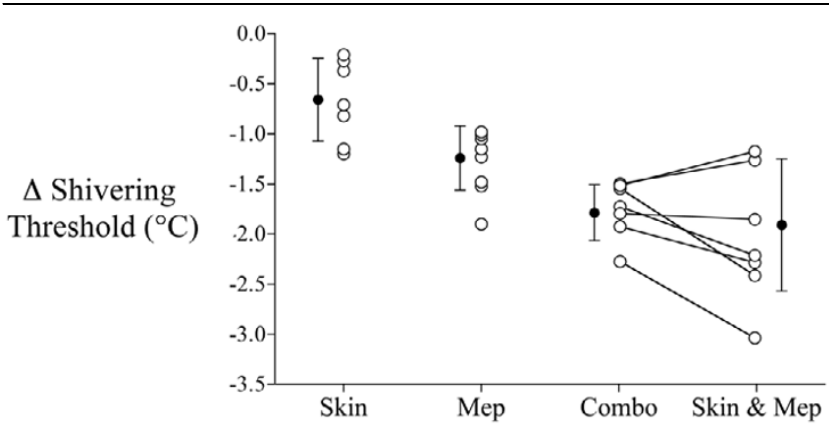

Reductions in the shivering threshold versus control. Bars indicate means \pm standard deviation. Combo, actual effect of skin warming plus meperidine; Mep, meperidine; Skin, skin warming; Skin \& Mep, calculated additive effect of skin warming plus meperidine.

In the majority of clinical mild hypothermia studies, general anaesthesia that patients received was often combined with generous amounts of muscle relaxants to suppress shivering. Although anaesthetics reduce shivering and vasoconstriction thresholds by $2^{\circ} \mathrm{C}$ to $3^{\circ} \mathrm{C}$, these drugs are, unsurprisingly, not the first choice for induction of mild hypothermia in the awake patient; they cause significant sedation and respiratory depression and jeopardise airway patency.

Consequently, numerous studies have searched for other drugs or drug combinations that lower vasoconstriction and shivering thresholds. One of the most effective anti-shivering drugs has proven to be meperidine [32,33]. Large plasma concentrations of meperidine, when used as a single drug, are necessary to reduce shivering thresholds to below $34^{\circ} \mathrm{C}$, which leads to sedation and respiratory depression. Smaller doses of meperidine in combination with other drugs (buspirone [14], dexmedetomidine [15], or magnesium [34]) have therefore been evaluated. The combination of meperidine and the anxiolytic drug buspirone has been the most effective. Mokhtarani and colleagues [14] demonstrated synergistic properties of this particular combination in contrast to other combinations. The combination of a relatively small dose of meperidine $(0.3 \pm 0.1 \mu \mathrm{g} / \mathrm{ml})$ and a single dose of buspirone (30 mg orally) was able to lower the volunteers' shivering threshold to $33.4^{\circ} \mathrm{C} \pm 0.7^{\circ} \mathrm{C}$.

In the present study, we used meperidine in combination with skin surface warming and targeted a meperidine plasma level of $0.9 \mu \mathrm{g} / \mathrm{ml}$. This combination (meperidine plus skin warming) has also been tested and used for the induction/maintenance of mild hypothermia with endovascular cooling in several clinical pilot studies in awake patients. Dixon and colleagues [35] used a combination of meperidine (75 to $100 \mathrm{mg}$ loading dose, followed by 25 to $35 \mathrm{mg} /$ hour continuously), skin warming, and oral buspirone ( 30 to $60 \mathrm{mg}$ orally) to induce mild hypothermia $\left(33.2^{\circ} \mathrm{C}\right.$ core temperature) in 21 patients during coronary intervention for acute myocardial infarction. They reported good feasibility with mild shivering in nine patients.
Leslie and colleagues [36] reported that a combination of a low level of meperidine (target plasma level: $0.4 \mathrm{mg} / \mathrm{ml}$ ) and skin warming in 10 patients scheduled for neurosurgery was insufficient to prevent shivering. However, study results have also shown a large range of meperidine levels $(0.1$ to $0.9 \mu \mathrm{g} /$ $\mathrm{ml}$ ) and therefore have to be interpreted with caution. In a pilot study by De Georgia and colleagues [37], 18 ischaemic stroke patients were cooled to $33^{\circ} \mathrm{C}$ using a combination of meperidine ( 50 to $75 \mathrm{mg}$ loading dose, followed by 25 to 35 $\mathrm{mg} /$ hour continuously), skin warming, and oral buspirone (60 $\mathrm{mg}$ ). The hypothermia group had a significantly higher incidence of intubations compared to 22 normothermic patients. The authors stated that it was unclear whether severity of disease or drug-induced sedation caused the difference. In a recent feasibility study, Guluma and colleagues [38] used a combination of meperidine (loading dose $1 \mathrm{mg} / \mathrm{kg}$, followed by $30 \mathrm{mg} /$ hour continuously) and skin warming to induce core hypothermia $\left(33.8^{\circ} \mathrm{C}\right)$ in 10 ischaemic stroke patients and reported satisfactory results.

However, only in the study by Leslie and colleagues [36] were meperidine levels measured and sedation assessed with a validated scale; in none of the aforementioned studies was the interaction between meperidine and skin warming examined. In contrast, by means of an approach described by Slinker [29], our present volunteer study is able to demonstrate an additive interaction between meperidine and skin warming.

Our study results are in accordance with those of previous studies. Using comparable levels of meperidine $(\approx 1 \mu \mathrm{g} / \mathrm{ml})$, Ikeda and colleagues [39] showed a decrease of the shivering threshold to $34.8^{\circ} \mathrm{C} \pm 1.0^{\circ} \mathrm{C}(10$ volunteers, cooling with intravenous cold fluid). The shivering threshold results on the meperidine day of our study are slightly lower $\left(34.2^{\circ} \mathrm{C} \pm\right.$ $0.2^{\circ} \mathrm{C}$ ), most likely because our volunteers had higher mean skin temperatures. In a skin warming study by Alfonsi and colleagues [21], forced-air warming decreased the shivering threshold of postoperative patients by $\approx-0.4^{\circ} \mathrm{C}$ (18 patients, forced-air warming). Our results show a slightly larger decrease of $\approx-0.6^{\circ} \mathrm{C}$ under comparable mean skin temperatures. Skin warming reduces oxygen consumption. Consequently, in volunteers on skin warming days, the threshold according to the present study's definition of shivering ( $+20 \%$ increase in oxygen consumption) is reached at a relatively lower core temperature, which may explain the abovementioned difference.

We used the combination of meperidine and skin warming in healthy volunteers only for induction of mild hypothermia. If our treatment had been applied for more than 24 hours, meperidine toxicity may well have become an important issue. Repeated doses of meperidine can induce feelings of shakiness, seizures, tremor, mood changes, and muscle weakness. Norpethidine, a meperidine metabolite, is most likely responsible [40] and correlates with the side effects of meperidine 
[41]. Patients with renal insufficiency are particularly affected because they tend to accumulate norpethidine faster [42]. Renal insufficiency therefore has to be considered a relative contraindication to anti-shivering drug combinations that include meperidine.

In the present study, core hypothermia was induced by intravenous infusion of cold fluid (Ringer lactate, $4^{\circ} \mathrm{C}$ ). This method has also been used successfully for induction of hypothermia in several clinical studies in patients with various types of neurologic injuries [43] and in patients after cardiac arrest $[44,45]$. Direct core cooling with cold-fluid infusion or intravenous cooling catheters has several advantages over conventional surface cooling. It is faster because heat is removed directly from the core rather than being required to pass through peripheral tissues, which insulate the core [46]. Core cooling can easily be combined with simultaneous skin surface warming. Finally, external cooling can become more difficult once core temperature is below the vasoconstriction threshold; this issue does not apply to cold-fluid cooling. However, despite the surprisingly good tolerance of fluid cooling by stroke or cardiac arrest patients, cold-fluid cooling may be an option for induction of hypothermia only, and other techniques (for example, an intravenous cooling catheter) are necessary for maintenance of hypothermia. We restricted core cooling rates to a range of $1^{\circ} \mathrm{C} /$ hour to $2^{\circ} \mathrm{C} /$ hour as we had previously shown that similar rates of skin surface cooling do not directly affect the shivering threshold and are unlikely to produce dynamic thermoregulatory responses [25].

A limitation of our study is that it was conducted in young, healthy volunteers. Results from volunteer studies cannot always be extrapolated to clinical situations. It is not unlikely that meperidine-induced sedation-only very mild in healthy volunteers-may have a bigger impact on patients after cardiac arrest or stroke.

In the present study, we evaluated sedation with the validated OAA/S scale [28]. Although this scale does not detect subtle degrees of sedation, it is unlikely that these subtle changes are clinically relevant in the context of stroke and other life-threatening conditions. More relevant are respiratory depression and ensuing hypercapnia, which limit the administration of meperidine in typical ward settings. In our study, end-tidal $\mathrm{PCO}_{2}$ (partial pressure of carbon dioxide) did not increase and no signs of respiratory depression could be observed.

\section{Conclusion}

A combination of meperidine and skin surface warming reduced the shivering threshold to $33.8^{\circ} \mathrm{C} \pm 0.2^{\circ} \mathrm{C}$ via an additive interaction and produced only very mild sedation and no respiratory toxicity. This combination can therefore be considered a recommendable and feasible regimen for induction and maintenance of therapeutic mild hypothermia.

\section{Key messages}

- Meperidine and skin surface warming additively reduced the shivering and vasoconstriction thresholds.

- A combination of meperidine $(\approx 0.9 \mu \mathrm{g} / \mathrm{ml}$ plasma level) and skin surface warming lowered the shivering threshold to $33.8^{\circ} \mathrm{C} \pm 0.2^{\circ} \mathrm{C}$ and allowed the induction of mild therapeutic hypothermia with only very mild sedation and no respiratory toxicity.

\section{Competing interests}

The authors declare that they have no competing interests.

\section{Authors' contributions}

OK conceived the study, drafted the manuscript, performed the statistical analysis, and performed the volunteer experiments. SZA conceived the study and performed the volunteer experiments. SZ, CH and MM performed the volunteer experiments. RL performed the meperidine plasma level analysis. AK conceived the study and drafted the manuscript. All authors read and approved the final version of the manuscript.

\section{Acknowledgements}

This work was supported by the Research Fund of the Department of Anaesthesia, University of Bern, Switzerland. OK was funded by the Scholarship of the Swiss Confederation for University Studies. Thermocouples were donated by Mallinckrodt Inc. (Hazelwood, MO, USA). The Gaymar water mattress was donated by Nufer Medical AG (Gümligen, Switzerland).

\section{References}

1. Busto R, Dietrich WD, Globus MY, Ginsberg MD: The importance of brain temperature in cerebral ischemic injury. Stroke 1989, 20:1113-1114.

2. Karibe H, Chen J, Zarow GJ, Graham SH, Weinstein PR: Delayed induction of mild hypothermia to reduce infarct volume after temporary middle cerebral artery occlusion in rats. $J$ Neurosurg 1994, 80:112-119.

3. Xue D, Huang ZG, Smith KE, Buchan AM: Immediate or delayed mild hypothermia prevents focal cerebral infarction. Brain Res 1992, 587:66-72.

4. Bernard SA, Buist M: Induced hypothermia in critical care medicine: a review. Crit Care Med 2003, 31:2041-2051.

5. Miki T, Liu GS, Cohen MV, Downey JM: Mild hypothermia reduces infarct size in the beating rabbit heart: a practical intervention for acute myocardial infarction? Basic Res Cardiol 1998, 93:372-383.

6. Schwartz LM, Verbinski SG, Vander Heide RS, Reimer KA: Epicardial temperature is a major predictor of myocardial infarct size in dogs. $J$ Mol Cell Cardiol 1997, 29:1577-1583.

7. Hypothermia after Cardiac Arrest Study Group: Mild therapeutic hypothermia to improve the neurologic outcome after cardiac arrest. N Engl J Med 2002, 346:549-556.

8. Bernard SA, Gray TW, Buist MD, Jones BM, Silvester W, Gutteridge G, Smith K: Treatment of comatose survivors of out-ofhospital cardiac arrest with induced hypothermia. $N$ Engl $J$ Med 2002, 346:557-563.

9. Xiong J, Kurz A, Sessler DI, Plattner O, Christensen R, Dechert M, Ikeda $T$ : Isoflurane produces marked and nonlinear decreases in the vasoconstriction and shivering thresholds. Anesthesio/ogy 1996, 85:240-245.

10. Kurz A, Xiong J, Sessler DI, Dechert M, Noyes K, Belani K: Desflurane reduces the gain of thermoregulatory arteriovenous shunt vasoconstriction in humans. Anesthesiology 1995, 83:1212-1219. 
11. Hanagata K, Matsukawa T, Sessler DI, Miyaji T, Funayama T, Koshimizu M, Kashimoto S, Kumazawa T: Isoflurane and sevoflurane produce a dose-dependent reduction in the shivering threshold in rabbits. Anesth Analg 1995, 81:581-584.

12. Annadata R, Sessler DI, Tayefeh F, Kurz A, Dechert M: Desflurane slightly increases the sweating threshold but produces marked, nonlinear decreases in the vasoconstriction and shivering thresholds. Anesthesiology 1995, 83:1205-1211.

13. Kurz A, lkeda T, Sessler DI, Larson MD, Bjorksten AR, Dechert M, Christensen R: Meperidine decreases the shivering threshold twice as much as the vasoconstriction threshold. Anesthesio/ogy 1997, 86:1046-1054.

14. Mokhtarani M, Mahgoub AN, Morioka N, Doufas AG, Dae M, Shaughnessy TE, Bjorksten AR, Sessler DI: Buspirone and meperidine synergistically reduce the shivering threshold. Anesth Analg 2001, 93:1233-1239.

15. Doufas AG, Lin CM, Suleman MI, Liem EB, Lenhardt R, Morioka N, Akca O, Shah YM, Bjorksten AR, Sessler DI: Dexmedetomidine and meperidine additively reduce the shivering threshold in humans. Stroke 2003, 34:1218-1223.

16. Piper SN, Maleck WH, Boldt J, Suttner SW, Schmidt CC, Reich DG: A comparison of urapidil, clonidine, meperidine and placebo in preventing postanesthetic shivering. Anesth Analg 2000, 90:954-957.

17. Alfonsi P, Adam F, Passard A, Guignard B, Sessler DI, Chauvin M: Nefopam, a nonsedative benzoxazocine analgesic, selectively reduces the shivering threshold in unanesthetized subjects. Anesthesiology 2004, 100:37-43.

18. Doufas AG, Wadhwa A, Lin CM, Shah YM, Hanni K, Sessler DI: Neither arm nor face warming reduces the shivering threshold in unanesthetized humans. Stroke 2003, 34:1736-1740.

19. Cheng C, Matsukawa T, Sessler DI, Ozaki M, Kurz A, Merrifield B, $\mathrm{Lin} \mathrm{H}$, Olofsson $\mathrm{P}$ : Increasing mean skin temperature linearly reduces the core-temperature thresholds for vasoconstriction and shivering in humans. Anesthesiology 1995, 82:1160-1168.

20. Takada K, Clark DJ, Davies MF, Tonner PH, Krause TK, Bertaccini E, Maze M: Meperidine exerts agonist activity at the alpha(2B)adrenoceptor subtype. Anesthesiology 2002, 96:1420-1426.

21. Alfonsi P, Nourredine KE, Adam F, Chauvin M, Sessler DI: Effect of postoperative skin-surface warming on oxygen consumption and the shivering threshold. Anaesthesia 2003, 58:1228-1234.

22. Wyss CR, Brengelmann GL, Johnson JM, Rowell LB, Niederberger $M$ : Control of skin blood flow, sweating, and heart rate: role of skin vs. core temperature. J Appl Physiol 1974, 36:726-733.

23. Austin KL, Stapleton JV, Mather LE: Pethidine clearance during continuous intravenous infusions in postoperative patients. Br J Clin Pharmacol 1981, 11:25-30.

24. Mather LE, Tucker GT, Pflug AE, Lindop MJ, Wilkerson C: Meperidine kinetics in man. Intravenous injection in surgical patients and volunteers. Clin Pharmacol Ther 1975, 17:21-30.

25. Lopez M, Sessler DI, Walter K, Emerick T, Ozaki M: Rate and gender dependence of the sweating, vasoconstriction, and shivering thresholds in humans. Anesthesiology 1994, 80:780-788.

26. Sessler DI, McGuire J, Moayeri A, Hynson J: Isoflurane-induced vasodilation minimally increases cutaneous heat loss. Anesthesiology 1991, 74:226-232.

27. Rubinstein $\mathrm{EH}$, Sessler DI: Skin-surface temperature gradients correlate with fingertip blood flow in humans. Anesthesiology 1990, 73:541-545.

28. Chernik DA, Gillings D, Laine $H$, Hendler J, Silver JM, Davidson AB, Schwam EM, Siegel JL: Validity and reliability of the Observer's Assessment of Alertness/Sedation Scale: study with intravenous midazolam. J Clin Psychopharmacol 1990, 10:244-251.

29. Slinker BK: The statistics of synergism. J Mol Cell Cardiol 1998, 30:723-731.

30. Nolan JP, Morley PT, Hoek TL, Hickey RW: Therapeutic hypothermia after cardiac arrest. An advisory statement by the Advancement Life support Task Force of the International Liaison committee on Resuscitation. Resuscitation 2003, 57:231-235.

31. Nolan JP, Deakin CD, Soar J, Bottiger BW, Smith G: European Resuscitation Council guidelines for resuscitation 2005. Section 4. Adult advanced life support. Resuscitation 2005, 67(Suppl 1):S39-86.
32. Kurz M, Belani KG, Sessler DI, Kurz A, Larson MD, Schroeder M, Blanchard D: Naloxone, meperidine, and shivering. Anesthesiology 1993, 79:1193-1201.

33. Terasako K, Yamamoto M: Comparison between pentazocine, pethidine and placebo in the treatment of post-anesthetic shivering. Acta Anaesthesiol Scand 2000, 44:311-312.

34. Zweifler RM, Voorhees ME, Mahmood MA, Parnell M: Magnesium sulfate increases the rate of hypothermia via surface cooling and improves comfort. Stroke 2004, 35:2331-2334.

35. Dixon SR, Whitbourn RJ, Dae MW, Grube E, Sherman W, Schaer GL, Jenkins JS, Baim DS, Gibbons RJ, Kuntz RE, et al:: Induction of mild systemic hypothermia with endovascular cooling during primary percutaneous coronary intervention for acute myocardial infarction. J Am Coll Cardiol 2002, 40:1928-1934.

36. Leslie K, Williams D, Irwin K, Bjorksten AR, Sessler DI: Pethidine and skin warming to prevent shivering during endovascular cooling. Anaesth Intensive Care 2004, 32:362-367.

37. De Georgia MA, Krieger DW, Abou-Chebl A, Devlin TG, Jauss M, Davis SM, Koroshetz WJ, Rordorf G, Warach S: Cooling for Acute Ischemic Brain Damage (COOL AID): a feasibility trial of endovascular cooling. Neurology 2004, 63:312-317.

38. Guluma KZ, Hemmen TM, Olsen SE, Rapp KS, Lyden PD: A trial of therapeutic hypothermia via endovascular approach in awake patients with acute ischemic stroke: methodology. Acad Emerg Med 2006, 13:820-827.

39. Ikeda T, Sessler DI, Tayefeh F, Negishi C, Turakhia M, Marder D, Bjorksten AR, Larson MD: Meperidine and alfentanil do not reduce the gain or maximum intensity of shivering. Anesthesiology 1998, 88:858-865.

40. Plummer JL, Gourlay GK, Cmielewski PL, Odontiadis J, Harvey I: Behavioural effects of norpethidine, a metabolite of pethidine, in rats. Toxicology 1995, 95:37-44.

41. Kaiko RF, Foley KM, Grabinski PY, Heidrich G, Rogers AG, Inturris $\mathrm{CE}$, Reidenberg MM: Central nervous system excitatory effects of meperidine in cancer patients. Ann Neurol 1983, 13:180-185

42. Drayer DE: Pharmacologically active drug metabolites: therapeutic and toxic activities, plasma and urine data in man, accumulation in renal failure. Clin Pharmacokinet 1976, 1:426-443.

43. Polderman $\mathrm{KH}$, Riinsburger ER, Peerdeman SM, Girbes AR: Induction of hypothermia in patients with various types of neurologic injury with use of large volumes of ice-cold intravenous fluid. Crit Care Med 2005, 33:2744-2751.

44. Kim F, Olsufka M, Carlbom D, Deem S, Longstreth WTJ, Hanrahan $M$, Maynard C, Copass MK, Cobb LA: Pilot study of rapid infusion of $2 \mathrm{~L}$ of 4 degrees $\mathrm{C}$ normal saline for induction of mild hypothermia in hospitalized, comatose survivors of out-ofhospital cardiac arrest. Circulation 2005, 112:715-719.

45. Kliegel A, Losert H, Sterz F, Kliegel M, Holzer M, Uray T, Domanovits $\mathrm{H}$ : Cold simple intravenous infusions preceding special endovascular cooling for faster induction of mild hypothermia after cardiac arrest-a feasibility study. Resuscitation 2005, 64:347-351

46. Plattner O, Kurz A, Sessler DI, lkeda T, Christensen R, Marder D, Clough D: Efficacy of intraoperative cooling methods. Anesthesiology 1997, 87:1089-1095. 